\title{
Saunaların Yapım Teknikleri ve Tek Kişilik Konut Tipi Sauna Örneği
}

\author{
Mustafa ALTINOK ${ }^{1}$, Barış KALE ${ }^{2}$, Mehmet YAŞAR $^{3 *}$, Ş. Şadiye YAŞAR ${ }^{3}$, Elif ALKAN ${ }^{4}, M$. \\ Said FIDAN ${ }^{4}$

\footnotetext{
${ }^{1}$ Gazi Üniversitesi Teknoloji Fakültesi A ̆gaç Işleri Endüstri Mühendisliği Bölümü, Ankara

${ }^{2}$ Dumlupınar Üniversitesi Fen Bilimleri Enstitüsü Mobilya ve Dekorasyon Eğitimi Anabilim Dall, Kütahya

${ }^{3}$ Gümüşhane Üniversitesi Gümüşhane Meslek Yüksekokulu Tasarım Bölümü, Gümüşhane

${ }^{4}$ Gümüşhane Üniversitesi Fen Bilimleri Enstitüsü Ormancılık ve Çevre Bilimleri Anabilim Dall, Gümüşhane
}

Geliş tarihi/Received 10.07.2015

Düzeltilerek geliş tarihi/Received in revised form 06.01.2016

Kabul tarihi/Accepted 11.01.2016

\begin{abstract}
$\ddot{O}_{z e t}$
Doğada, sicak ve soğuk olmak üzere birbirine zıt iki kutup vardır. Sauna bu tezatların bir uygulama mekanıdır. Sauna, hava ve su vasitasıyla soğutulan bir sicak hava banyosudur. Bu banyo ile insan bedeni, soğuk ile sıcak arasındaki doğanın mücadelesini küçük çapta da olsa uygulamasını yaşamaktadır. Buna göre; sauna, sicak ile soğuğun etkileri arasındaki sonsuz çekişmeyi temsil etmektedir. Sauna, bu iki büyük tesiri ideal bir şekilde bünyesinde toplamaktadır. Bu çalışmada, saunaların yapım teknikleri hakkında literatür taramaları ve tek kişilik konut tipi sauna yapımı örneklendirilmiştir. Çallşma sonunda; elde edilen teknik dokümanlar ve edinilen tecrübeler ile bütün tasarlanmış saunalara yeni bir alternatif olarak, konut tipi mekanlar için banyoda tek kişilik bir sauna modeli geliştirilmeye çalışılmıştır.
\end{abstract}

Anahtar kelimeler: Sauna, Yapım Teknikleri, Konut Tipi Sauna

\section{Production Techniques of Saunas and Single Residence Type Sauna Sample}

\begin{abstract}
In nature, including hot and cold are two opposite poles. An application of this contrast sauna venue. Sauna, air and water is cooled by means of a hot air bath. The human body with this bath, hot and cold nature of the struggle between the application lives on a small scale though. Accordingly; saunas, hot and cold endless contention between the effects represents. Sauna, these two great influence has incorporated an ideal way. In this study literature review was made about construction techniques of saunas and production of single residence type sauna. At the end of the study; in bath a single sauna model is tried to developed for residential type places as a new alternative to all designed saunas which is designed with obtained technical documents and gained experiences.
\end{abstract}

Keywords: Sauna, Production Techniques, Residence Type Sauna

\footnotetext{
*Mehmet YAŞAR, mehmetyasar@gumushane.edu.tr, Tel: (0456) 233 78 08/2927 


\section{Giriş}

Sauna, kuru ve sicak hava ile yapılan bir banyo türüdür. $\mathrm{Bu}$ hava içerisinde kısa aralıklarla buhar verilmekte ve aynı zamanda soğuk hava ve soğuk su ile soğukluk tahriki de oluşturmaktadır. Bu nedenle sauna, güzel bir uyum içerisinde uygulanan doğal tahriklerin kombinasyonu halini almaktadır.

Konum içeriği ve şekli, yeni bulunmuş olmayıp doğrudan doğruya tabiat ile ilgili ve buna bağlı bir olaydır. Buna göre sauna bir buhar banyosu olmayıp, sicak hava ile yapılan bir banyo türüdür. Rutubet derecesi çok az olan bu hava içerisindeki bütün hastalık mikroplar öldüğünden, herhangi bir hastalığın doğmasına olanak tanımamaktadır. Sauna insan bedeni bir rahatlik vermektedir.

Diğer banyo türleri ile saunayı kıyaslamak anlamsızdır. Sauna için bir söz söylemek gerekirse; sauna binlerce ylldan bugüne gelen iyi bir banyo türüdür, bundan sonrada yine böyle kalacaktır (Kale, 2006).

\subsection{Saunaların Tarihsel Gelişimi}

Saunanın ana vatanı Finlandiya'dır. Sauna bu ülkede doğup bu topraklarda bugünkü çağdaş düzeyine ulaşmıştır. Bunun en doğal sebebi bu ülkelerin ve diğer kuzey ülkelerinin soğuk olması ve terleme olayına daha çok ihtiyaç duyulmasıdır. Finlandiya ve diğer kuzey ülkeleri şuanda sauna banyosundan en çok faydalanan ülkelerdir. Bundan dolayı sauna teknolojinde en ileri ülkelerdir. Arkeologların raporlarına göre bu ülkelerde sauna 9000 yıldan beri vardır (Kale, 2006).

Sauna en büyük aşamayı son yüzyıl içinde yapmıştır. Bu yüzyılda sauna hem dumanlı olmaktan kurtulmuş hem de prefabrik olarak evlere taşınmıştır. Yani sauna elektrikli hale veya diğer bir değişle çağdaş duruma ulaşmıştır. Bu gelişme bu yüzyılda olmuştur (Kale, 2006).

Bugün Finlandiya'nın nüfusu 4.5 milyon olmasına rağmen mevcut olan sauna adedi yaklaşık 600.000'dir. İstatistik raporlarına göre her Finli yılda 61 defa sauna banyosu yapmaktadır. 20 yıl öncesine kadar, Finlilerin çoğunluğu saunada doğardı. Bugün dahi ülkenin iç kısım ve kasabalarında doğumların çoğunluğu saunada yapılmaktadır. İhtiyarlık yaşlarında dahi Finli, saunadan vazgeçmemektedir. Finlandiya'daki askeri birimlerin hizmet şartnamesinde, her askere haftada bir sauna banyosu zorunlu tutulmaktadır. Hatta Fin hükümetinin bugün dahi, haftada bir gün sauna günü vardır ve o gün hükümet erkanı sauna banyosuna girer ve orada devlet işlerini tartışırlar (Kale, 2006).

Özellikle son yirmi y1l içinde sauna, dünyanın çeşitli ülkelerinde hızla yayılmış, hatta 30 yıl öncesine kadar sauna adı bilinmeyen yerlere dahi girmiştir. Saunanın bütün ülkelerde hızla yayılması ve bu ülkelerde tutulmasının belli başlı sebebi, bilimin son 30 y1l içinde saunanın cildi, çok iyi bir şekilde temizlediği ve çeşitli hastalıkları önlediğini ispat etmiş olmasıdır. Ayrıca saunayı kullanan kişilerin sauna hakkındaki olumlu ifadeleri ile sauna kullanımı insanlar arasında hızla yayılmıştır. $\mathrm{Bu}$ nedenle dünyada hemen her ülkede sauna bulunmaktadır (Neufert, 1983).

Bugün İsveç'te tahminen 20.000 sauna bulunmaktadır. $\mathrm{Bu}$ saunalardan yaklaşık 2.000'i son yıllarda devlet desteği ile yeniden inşa ettirilmiştir. Doğu Almanya bölgesinde yaklaşık 150 sauna işletmesi vardır. Avusturya'da yaklaşık 120, İsviçre'de ise 4.7 milyon nüfusun kullanımında 500'den fazla sauna bulunmaktadır. Keza ancak 1945 yılından itibaren saunanın yayılmaya başladığı Batı Almanya'da bugün 1500'den fazla sauna mevcut bulunmaktadır (Kale, 2006).

I. Bölüm: 1864-1925 periyodunu kapsar ve halk geleneklerinin üzerine toplanmıştır.

II. Bölüm: 1925-1960 y1lları arsında görülen sauna geleneklerinin ana değişiklerini içerir.

III. Bölüm: Sadece 1960 ve sonrası periyoduna kısa bir başlangıçtır. Amerika'da sauna gelişiminin bir dönemidir (Kale, 2006). 
Günümüzde genel olarak kullanılan saunalar dört çeşittir. $\mathrm{Bu}$ sınıflandırmanın dışında saunalar 1sınma sistemlerine göre ve bank sayılarına göre sınıflandırılmaktadır. $Y a z$ saunalarl; yaz saunaları basittir. Bu saunalar hafif bir yapıya sahiptir. Ve mümkün olduğu kadar ucuz olarak inşa edilir. Bu tip sauna genelde yalnız başına bir sauna odası ya da bir revak'1 kapsar. Yaz saunaları su bağlantısını kolaylaştırmak için tercihen deniz kıyısı, göl veya çay kenarına yerleştirilir (Kale, 2006). Tatil saunaları; tatil saunaları genellikle geçicidir. Fakat yaz saunalarından daha karmaşık bir yapıya sahiptir. Yalıtım ve ısıtma kış aylarına göre yapılmış olmalıdır. Sauna binasına ilaveten, havlu içinde odun depolama alanına ve temiz bir klozet veya wc'ye sahip olmalıdır. Eğer, sauna kışın kullanılıyor ise, diğer odalardan soğuk hava girişini önlemek için bir antreye sahip olmalıdır. Çünkü bu tür tatil saunası ve bir sauna binası belki tipik bir tatil evidir. Sauna odas1 ve banyo odas1 tatil evinde alan yetersizliğini telafi etmeye yardım eder. $E v$ içerisindeki saunalar; sürekli bir evdeki sauna, banyo, yatak odası veya mutfağa bitişik veya ayrı bir ünite olarak evin içine yerleştirilir. Eğer herhangi bir durumda mahzene ihtiyaç duyuluyorsa ve bina parseli küçük olduğundan sauna için başka bir çözüm yolu yoksa sauna mahzene de yerleştirilebilir. İyi bir havalandırma sağlamak ve evi yamaca inşa etmedikçe hava değişimi için bir yer ve 1ş1k almak zor olduğu için mahzende sauna genellikle tavsiye edilmez. Bununla beraber sauna bir yamaca yerleştirilebilir ve gün 1şığ1 ile aydınlatılabilir. Serinleme revağı ilaveten saunanın ön tarafina yapılabilir. $K_{l s ̧}$ saunaları; özellikle soğuk kuzey ülkelerinde yaygın olan kış saunaları, artık saunaların ev içine girmesiyle sayıları azalmaya başlamıştır. Kışın kendine ait güzelliği içinde sauna keyfi sürmek isteyenler için hala özelliğini korumaktadır (Kale, 2006).

Saunaları daha iyi tanımlayabilmek için şu şekilde sınıflandırma yapılabilir; Iç̧inde banyo yapabilen kişi sayısına göre: Tek kişilik saunalar, iki kişilik saunalar, üç kişilik saunalar, dört kişilik saunalar, altı kişilik saunalar, sekiz kişilik saunalar ve daha fazlasıdır. İçindeki Bank Sayısına Göre:
Banksız (portatif) sauna: Plastik, deri, vb. malzemelerden yapılmış dışarıdan sıcak hava üfleme ve ayakta banyo yapılan bir türdür. $\mathrm{Bu}$ tip sauna denilen kabinlere sauna denilemez ve saunanın tüm fonksiyonlarını yerine getiremez. Tek banklı sauna (bir yatma veya iki oturma pozisyonu). İki banklı sauna (bir yatma ve iki oturma pozisyonu). Üç banklı sauna (iki yatma ve bir oturma). Dört bank1 sauna (iki yatma ve iki oturma). Çok bankı sauna (genel saunalar). Yapılış Biçimlerine Göre: Portatif saunalar, sabit ev saunaları, prefabrik ev saunaları, sabit arazi saunaları, kütük saunalar, ahşap olmayan saunalardır. Isınma Biçimlerine Göre: Buhar banyoları, dumanlı saunalar, gazlı saunalar, sobalı saunalar ve elektrikli saunalardır. Bundan başka saunalar çeşitli biçimlerde sınıflandırılabilir. Örneğin bacalı, bacasız sauna veya genel, özel sauna gibi ancak belli başlı sınıflandırma sistemi yukarıdaki gibi yapılmaktadır. Isınma biçimine göre saunalar daha detaylı olarak aşağıdaki şekilde incelenebilir (Çetinbank ve Aksoy, 1987).

Saunaların doğru ve düzenli uygulanması sonucunda şu yararlar sağlanmaktadır;

Aşırı sıcaklık ile kandaki hastalık virüsleri yok edilir bu suretle bütün hastalıklara özellikle üşütmeye, mikrobik hastalıklara ve romatizmaya karşı dayanım gücü artar.

$\checkmark$ Terleme ile kandaki toksin maddeler atılır. Yani kana giden gida maddelerinin emilimi atılır. Yani kana giden gida maddelerinin emilimi artar ve kan maddelerden temizlenir.

$\checkmark$ Deri bol miktarda kanla beslenir. Dış doku genişler. Derinin koruma gücü artar ve "kan damarları idmanı" sağlanır.

$\checkmark$ İç organlardaki ve beyindeki kan dolaşımı yükselir. Bunun neticesinde vücuttaki bezlerin faaliyeti artar. Zihin açıklığı ve dimağın verimliği yükselir.

$\checkmark$ Kan dolaşımı doğal olarak hızlanır ve kalbi hafifletir.

$\checkmark$ Vücutta hastalıklara karşı direnç gösteren maddelerin oluşumuna engel olur.

$\checkmark$ Sinirleri dinlendirir.

Sauna, her bakımdan doğal olan bir tedavi yöntemini temsil etmektedir. Hastalıklardan 
korunmak, bunları tedavi etmek ve bütün organizmayı dayanıklı hale getirmek amaciyla sauna banyosunun düzenli olarak yapılması, doktorlar tarafindan tavsiye edilmektedir. Sauna bir halk banyosu olarak yapılması, doktorlar tarafindan tavsiye edilmektedir. Sauna bir halk banyosu, diğer yandan tedavi banyosudur (Kale, 2006).

\section{Sauna Yapım Teknikleri}

\subsection{Sauna Yapımı}

Günümüzde saunalar genellikle elektrik ile isıtılan saunalardır. Bundan dolayı yapım tekniklerinin geliştirilmesinde, elektrikli saunalara ağırlı verilmektedir. Ancak saunanın tarihi süreci içerisindeki yapım teknikleri de bilinmelidir. Sauna elektrik 1sitici ile 1sitılan sauna, sicak ve kuru hava banyosudur.

Sauna binanın herhangi bir katında bütün alanları bir arada olacak şekilde veya binadan ayrı olarak kagir yığma, betonarme, ahşap veya çelik karkas olarak inşa edilmeli ve yangından korunmak için TS 4156'ya uygun tedbirler alınmalıdır.

Dört duvar arasında yapilan saunalarda duvara yatay olarak $50 \mathrm{~cm}$ 'de bir dübellenen en az $45 \times 45 \mathrm{~mm}$ boylarında kereste 1 zgara ve üzerine düşey olarak çivi görünmeyecek bir şekilde geçmeli, lambri kaplama yapılmalı, tavan sehim yapmayacak bir şekilde ahşap kirişlemeye çakılan lambri ile kaplanmalı, duvar ve tavanda isı izolasyonu sağlanmalıdır (TSE, 1992).

Saunaların yapıları yeterli 1S1 yalıtımı sağlamalıdır. Duvarlar ve tavan tarafından 1sı depolanması azaltılmalıdır. Duvar ve tavandaki 1sı yalıtımı mümkün olduğu kadar kapalı olarak odanın iç tarafına yerleştirilmelidir. Mineral yünler gibi en düşük 1s1 depolama kapasiteli yalıtıcılar kullanılmalıdır (Çetinbank ve Aksoy, 1987).

Taş duvar mükemmel bir yalıtıcı olsa bile, taşın 1S1 depolama kapasitesi saunanın 1S1 özelliklerini bozar. Isıtma için $1 \mathrm{~m}^{2}$ taş duvar,
$2.5 \mathrm{~m}^{3}$ fazladan bir hacme tekamül eder (Çetinbank ve Aksoy, 1987).

Sicak hava saunanın tavanına doğru akar. Kuru hissedilen bir sauna bile her zaman bir dereceye kadar rutubetlidir. Rutubet her zaman sicak havadan soğuk havaya doğru hareket eder. Eğer buharın serbestçe hareketine izin verilirse buhar bariyeri, yalıtıcının dış kenarında bir yere toplanacak ve izolasyonu zayıflatacaktır ve yapıya zarar verecektir. Etkili havalandırma olduğu zaman, saunanın duvarlarında sızdırmazlık elamanlarına ihtiyaç kalmayacaktır (Otto, 1975).

Sauna odasının zemininin sıcaklığı yaklaşık $30{ }^{\circ} \mathrm{C}$ 'dir. Her zaman yalıtıcı gerekli değildir. Periyodik olarak kullanılan bir tatil saunası ve ya yaz saunasının zemini tamamen yalıtımsız olabilir. Döşemede ağaç malzeme kullanılacak ise tercihen basınç uygulanmış veya dış hava tesirlerine dayanıklı kontrplak kullanılmalıdır. İçinde ikamet edilen bir saunada, duvarlar, duvar iç yüzeyindeki bir buhar deliği ile yalıtılmalıdır. Aksi takdirde rutubet diğer alanlara nüfus ederek ve yapıya zarar verecektir. Sauna odasindan gelen rutubet, havalandirma vasitasiyla bacadan direk tahliye edilir (Kale, 2006).

Fin saunaları ilk zamanlarda orijinal olarak kütük ev tipi, tomruk konstrüksiyonludur. Yontulmuş tomruklar ve düzeltilmiş tahtalar, günümüzde de özellikle yaz saunalarında hala vazgeçilmeyen yap1 malzemesidir. Tomruk duvar "teneffüs eder" ifadesi yaygındı. Sauna odasında ki alçak basıncının bir sonucu olarak, dışarıdan gelen taze hava, duvarın alt tarafındaki aralıklardan ve çatlaklardan içeri girer. Sicak hava tomrukların üst tarafindaki aralıklardan dışarı hareket eder. Tomruk konstrüksiyonlu sauna, kullanımdan sonra hızlı havalandırma için hava deliğine ihtiyaç duymaktadir. Tomruk duvar, 1sitmada içerideki havayı emer, saunanın buna bağlı olarak sıcaklığı yavaş olarak değişir ve kişi üzerindeki ısı yayılımı yavaştır. Diğer taraftan tomruk konstrüksiyonlu sauna, aynı ebattaki bir prefabrik saunadan veya keresteden yapılmaktadır (Bozkurt, 1971). 
Tomruklar ev içinde kurulan saunaların duvarları içinde başarılı bir şekilde kullanılabilir. Ancak tomruk duvar ve ev duvarı arasında en azından 15 cm'lik bir boşluk bırakılmalıdır. Ancak bu surette tomruklar nefes olabilir. Daha sonra saunanın iç tarafını çevreleyen tavan ve duvarlarda bir buhar bariyerinin yerleştirilmesi gerekir. Tomruk duvarlar arasındaki hava sirkülasyonu, panel konstrüksiyonlu saunalarda görülmeyen hoş bir reçineli aroma kokusuna sahiptir.

\subsection{Sauna Yapımında Kullanılan Birleştirmeler}

Saunalar ahşaptan yapıldığı için kayıtlarının birleştirilmesinde ahşap birleştirme teknikleri ve diş tipleri kullanılmaktadır. Sauna yapımında kullanılan lambriler çok çeşitli olmaktadır. $\mathrm{Bu}$ birleştirmeler hem sağlamlık hem de estetik tercihlerden dolay1 kullanılmaktadır (Kale, 2006).

\subsection{Sauna Yapımına Kullanılan Ă̆açlar}

Sauna yapımında dikkat edilecek en önemli hususlardan birisinde kullanılacak olan ağacın seçimidir. Bir saunada sıcaklığın $130{ }^{\circ} \mathrm{C}^{\prime} \mathrm{ye}$ kadar çıktığı düşünülecek olursa, kullanılacak ağacın önemi daha iyi kavranır. Sadece kuzey ülkelerde yetişen yüksek kalite ağaçlar sauna için ideal olmaktadır.

Sauna duvar ve tavan panelleri üretiminde az reçine oranlı Fin Ladini, budaksız Fin Çamı veya Kanada Ladini kullanılmaktadır. Sauna oturma ranzalarında sırt ve baş yaslama aksesuarlarında ise Afrika menşeli bir ağaç olan Abachi veya Aspen kullanılmaktadır. Bu ağaçların en önemli özelliği 1sıyı tutmaması ve böylelikle cildi yakmamasıdır. İnsan vücudunun temas edeceği yerlerde mutlaka bu ahşaplar kullanılmalıdır. Ayrıca kıymıksız ve kolay temizlenebilir olması bu ağacın oturma ranzaları için en ideal ağaç yapmaktadır. Emprenye edilmiş ahşaplar sauna içerisinde kesinlikle kullanılmamalıdır (URL-1, 2006).

Türkiye'de sauna üretimi yapan belli başlı bazı firmalar saunayı genellikle Sedir, Kızıl Çam ve Köknar ağacından yapmaktadırlar.
Bunlara son zamanlarda dış ülkelerden gelen Tik, Kızıl Ağaç ve Abachi ağaçları da eklenmiştir. Ancak Türkiye açısından Sedir ve Kızıl Çam ideal ağaçlardır. Köknar ise dayanımının az olması ve yumuşaklığı dolayısıyla az tercih edilmektedir. Sedir ve Kızıl Çam ise pahalı olmasına rağmen dayanımı, sıcağa etkin oluşu ve genel görünümü nedeniyle tercih sebebidir. Sedir, dünyada ve ülkemizde az bulunan bir ağaçtır. Değerli ve çok pahalı bir ağaçtır. Sauna ise hacim olarak öyle küçümsenecek bir mamul değildir. Hatta oldukça fazla kereste kullanımını gerektirmektedir. Bunlar göz önüne alındığı taktirde sauna için en uygun ağaç ülkemizde de yetişen Kızılçam'dır. Ancak budaksız, çatlaksız, reçinesiz, düzgün gövdeli Kızılçam ağacı kullanılmalıdır.

Genel olarak dünyada sauna yapımından kullanılan ağaç türleri şunlardır; Sedir, Sarıçam, Kızılçam, Western Hemlock, Limba, Abachı, Parana Pine, Avrupa Göknarı, Ladin, Matenye African, Mohogany Afrika Cevizi, Yang Light Red Merant1, Teak, Kaliforniya $\mathrm{Su}$ Sediri, Dauglas Göknarı, Kiraz, Saplı Meşe, Karaağaç, Afzella, Aningeria, Okume, Gaboun, İroko, Mavingvi, Tiama, Agba, Tola, Bosse, Kestane, Alder, Beyaz Fin Çamı, Kavak, Kırmızı Sedir. Aspen, Kuzey Çamı, Kanada Ladini (URL-2, 2006).

\subsection{Panel (Modüler) Sauna Yapımı}

Günümüzde yaygın hale gelen panel sauna, hem daha ucuz hem de herkes tarafindan kolaylıkla sökülüp takılabildiğinden tercih edilmeye başlamıştır. Sauna kiti, eve geldikten sonra veya büyük marketlerden aldıktan sonra kurulum talimatlarına göre kurulmaktadır. Bütün gerekli olan aksesuarlar ve bağlantı elamanları da paketten çıkmaktadır.

Adım adım verilen saunada önce saunanın kurulacak yeri belirlenir. Daha sonra sauna köşe profilleri ve lambriler montaj talimatına uygun olarak kurulur. Tabanı ve duvarları monte edilen saunanın çatısı da montaj kurallarına göre yapılır. Daha sonra sauna iç düzenlemesi yapılır. İç düzenlemede havalandırma ve sürgülerinin montajı oldukça önemlidir. 


\subsection{Alternatif-Tek Kişilik Konut Tipi Sauna Yapımı}

Günümüzde tek kişilik $1 \mathrm{x} 1 \mathrm{~m}^{2}$ 'lik demonte sauna kabinlerinden 20x25 $\mathrm{m}^{2}$ 'lik otel saunalarına kadar çok çeşitli tip ve boyutlarda sauna üretilmektedir. Evlerde uygulanan saunalar için çok geniş bir mekana gerek olmadığı gibi, montajını gerçekleştirmek için yalnızca bir saat gibi kısa bir zaman yeteli olmaktadır. Estetik, emniyet, hijyen ve dayanıklılık gibi özelliklerin yanı sıra, sauna kabinlerinin tasarımında gözden kaçırılmaması gereken bir başka nokta, kullanım kapasitesidir. Saunayı tasarlarken, standart ölçülere göre kişi başına yaklaşık 0.8$1 \mathrm{~m}^{2}$ lik bir alan zorunluluğunu göz ardı etmemek gerekir (URL-3, 2006)

Normal ölçülerde bir banyo sauna için yeterli alanı sağlar. Banyo küvetinin kaldırılarak yerine, mekanın biçimine ve konumuna uygun saunanın ve yakınına duşa kabin monte edilmesi alan kazanımını sağlar. Böyle durumlarda, duşun bulunduğu kısımlardaki sauna dış duvarı seramikle, vinil kaplama malzemesi veya koruyucu vernikle suya karşı korunmalıdır. Yansımalı güvenlikli camdan sauna kapısı, yer döşemesi, sauna iç aksesuarları ve havalandırma düzeneği yat verniği ile suyun etkisine karşı korunmalıdır (Kale, 2006).

\subsection{Teknik Özellikleri}

1300x1300x2400 mm ölçülerinde demonte olarak düşünülen sauna banyoda küvetin yerine düşünülmüştür. Sauna yapımında, Türkiye'de yetişmesinden dolayı, sedir ve kızılçam ahşabı kullanılmıştır. Bu ahşapların işkenmesindeki kolaylık, görünüm ve sauna içerisne bıraktıkları güzel koku, insane tenine allerjik etki yapmaması, yüksek 1sı ve neme olan dayanıklılı̆̆1 tercih edilmiştir. Bir uzanma, birde oturma bankından oluşan sauna elektrikli soba ile 1sitılmaktadır. Şekil 1'de saunanın cm ölçü biriminde ön görünüşü verilmiştir. Soba oturma ve uzanma bank1 görülmektedir. Şekil 2'de saunanın üst görünüşü verilmiştir (Kale, 2006).

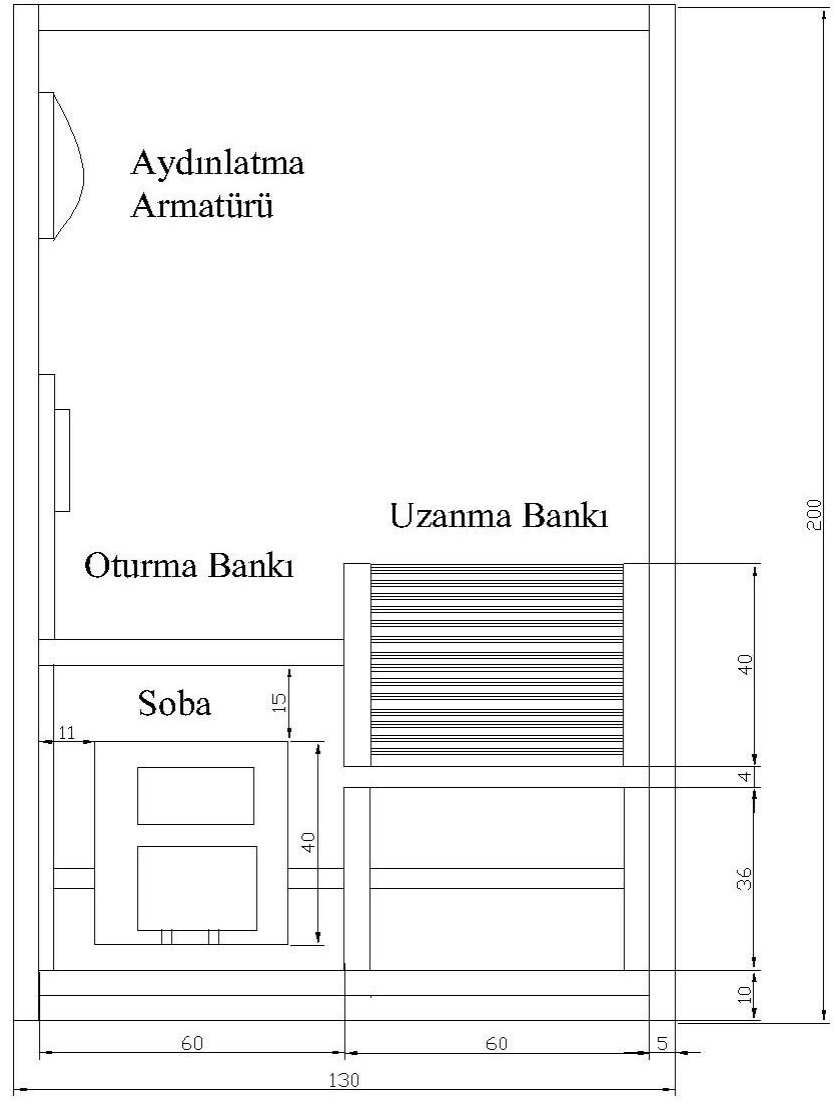

Şekil 1. Tek kişilik alternative sauna ön görünüş ve ölçüleri 


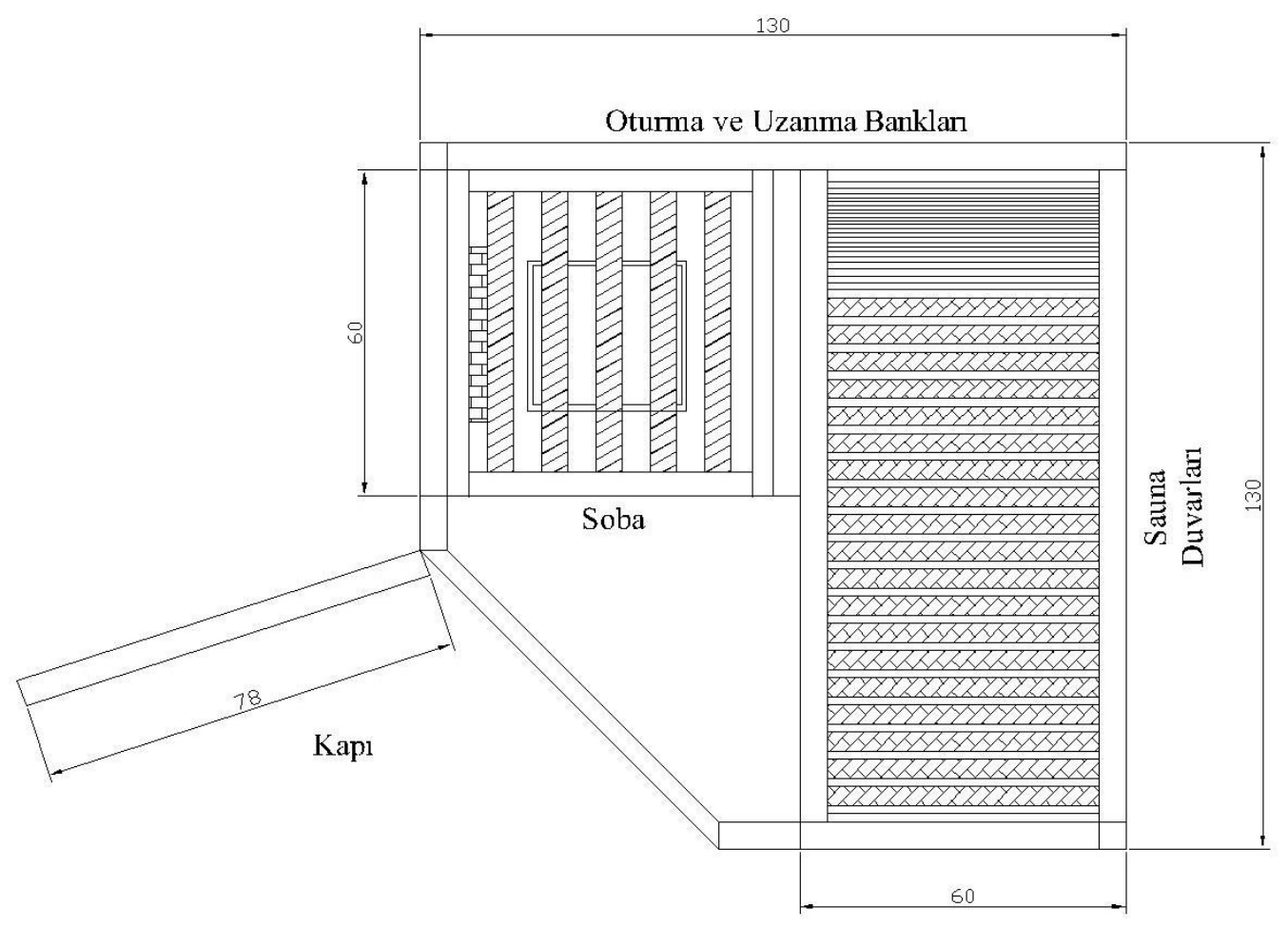

Şekil 2. Tek kişilik alternatif sauna üst plan görünüşü $(\mathrm{cm})$

Tamamen demonte olan sauna, 5 veya 4.5 cm'lik köşe profillerden çerçeve konstrüksiyon metoduna göre zivanalı ve kavelalı birleştirilmiş, istenildiğinde tekrar sökülebilmek amacıyla alyan başlı silindir çektirmeler ile sağlamlaştırılmıştır. Saunayı oluşturan bütün çerçeve elemanlarında ve lambrlerde erkek ve dişi zıvanalar paketlenmeden once hazırlanmıştır.

Karşılıklı köşe profilleri her iki yüzeyine kiniş açılmış sauna duvarlarını oluşturan iç ve dış lambriler bu kinişler üzerine dizilmiştir. Sunanın dış kısmında, müşterinin isteğine göre yatay veya dikey yönde birbirine zıvanalı geçmiş lambriler dizilmiş, saunanın iç kısmında ise, oluşan su damlacıklarının duvarlardan süzülmesini kolaylaştırmak için dikey yönde lambriler düşünülmüştür.İç ve dış lambrilrin kalınlığ $15 \mathrm{~mm}$ genişlikleri ise $100 \mathrm{~mm}$ olacaktır. İki lambri arasına, 1s1 yalıtımı için $15 \mathrm{~mm}$ 'lik mineral yün yalıtım malzemesi yerleştirilecektir. Mineral yün üzerine, sauna iç tarafına gelen kısma, istenilirse, nem izolasyonu için aliminyum kağıtta ilave edilebilir. Şekil 3'de köşe profillerin birleştirilmesi ve iç ve diş duvarlara lambrilerin dizilimi görülmektedir (Kale, 2006).

Sauna tabanında kaymayı engellemesi için demonte ahşap 1zgara düşünülmüştür. Sauna içerisindeki uzanma ve oturma bankına ait ahşap elemanlar ile kabin içi diğer aksesuarar ayrı bir paket içerisinde müşteriye sunulacak, montaj tahlimatına göre vidalanacaktır. Vidalar paslanmayan ve ahşap içine gömülecek şekilde havşalı olarak yapılmıştır.

Saunanın 1sitılmasinda kullanılan soba piyasada satılan kaliteli, emniyet tertibatl elektrikli sobadır. Bu soba oturma bankının altına yarleştirilmiştir. Bankla soba arasında ahşaba zarar vermeyecek bir mesafe bırakıllmıştır. Ayrıca bankın altına galvanize bir sac parçası da monte edilebilir.

Saunanın küçük olmasından dolayı sobanın bank altına yarleştirilmesi yerden bir kazanım sağlamıştır. Mekanın aydınlatılmasında gözü rahatsız etmeyecek ahşap ızgaralı veya örtülü $150{ }^{\circ} \mathrm{C}$ 'ye dayanıklı özel seramik duylu ve düşük watlı ampulle çalışan aplikler kullanılmıştır. 

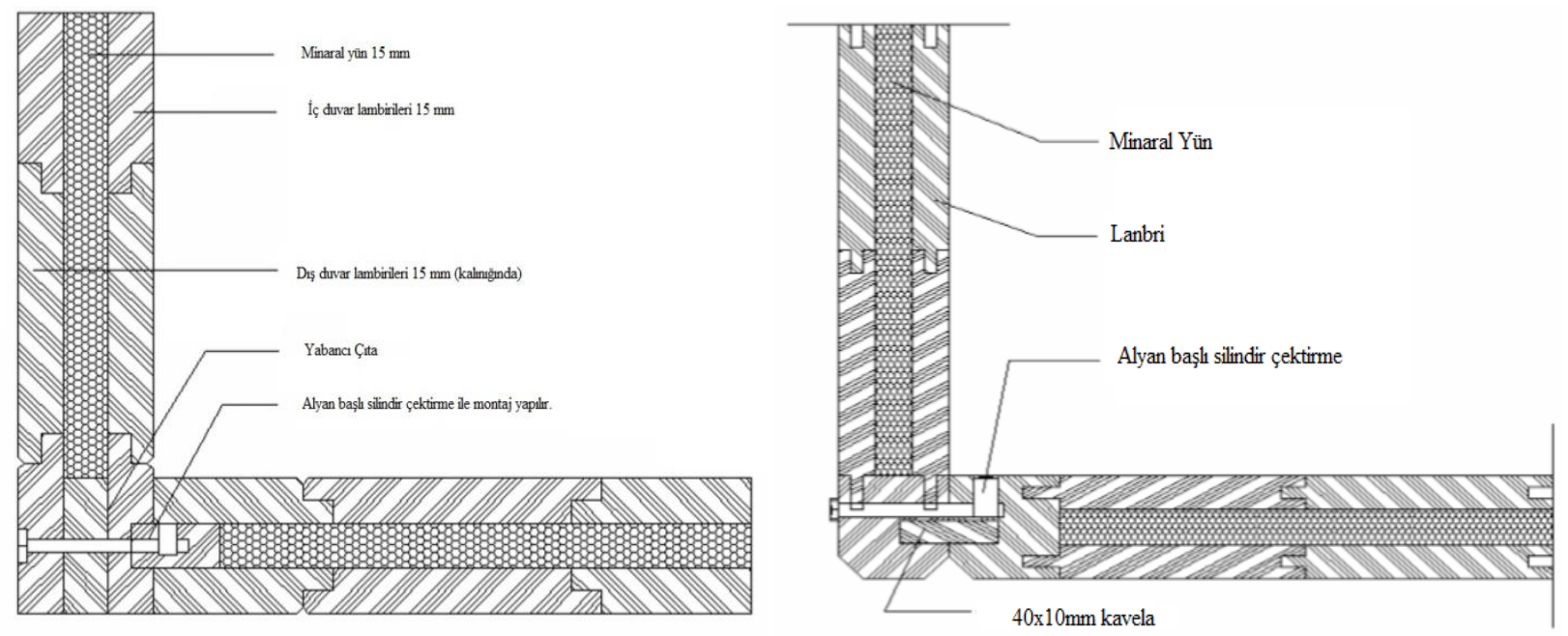

Şekil 3. Köşe profillerin birleştirilmesi ve iç ve dış duvarlara lambrilerin dizilimi

Sauna kapısı yerden kazanım sağlaması açısından sauna duvarlarına $45^{\circ}$, dir. Kap1 güvenlik açısından dışa doğru açılmalıdır. Kapının camı temperlenmiş özel güvenlikli bir camdır. Kapının üst kısmında havaandırma penceresi, alt kısmında ise temiz hava girişini sağlayacak bir 1zgara bulunmaktadır. $\mathrm{Bu}$ iki havalandırma bölümü ile saunada hava sirkülasyonu amaçlanmıștır. Şekil 4'de sauna kapısı ve havalandırma sistemi görülmektedir. Saunanın dış duvarlarının yatay lambriler şeklinde dizildiği görülmektedir.

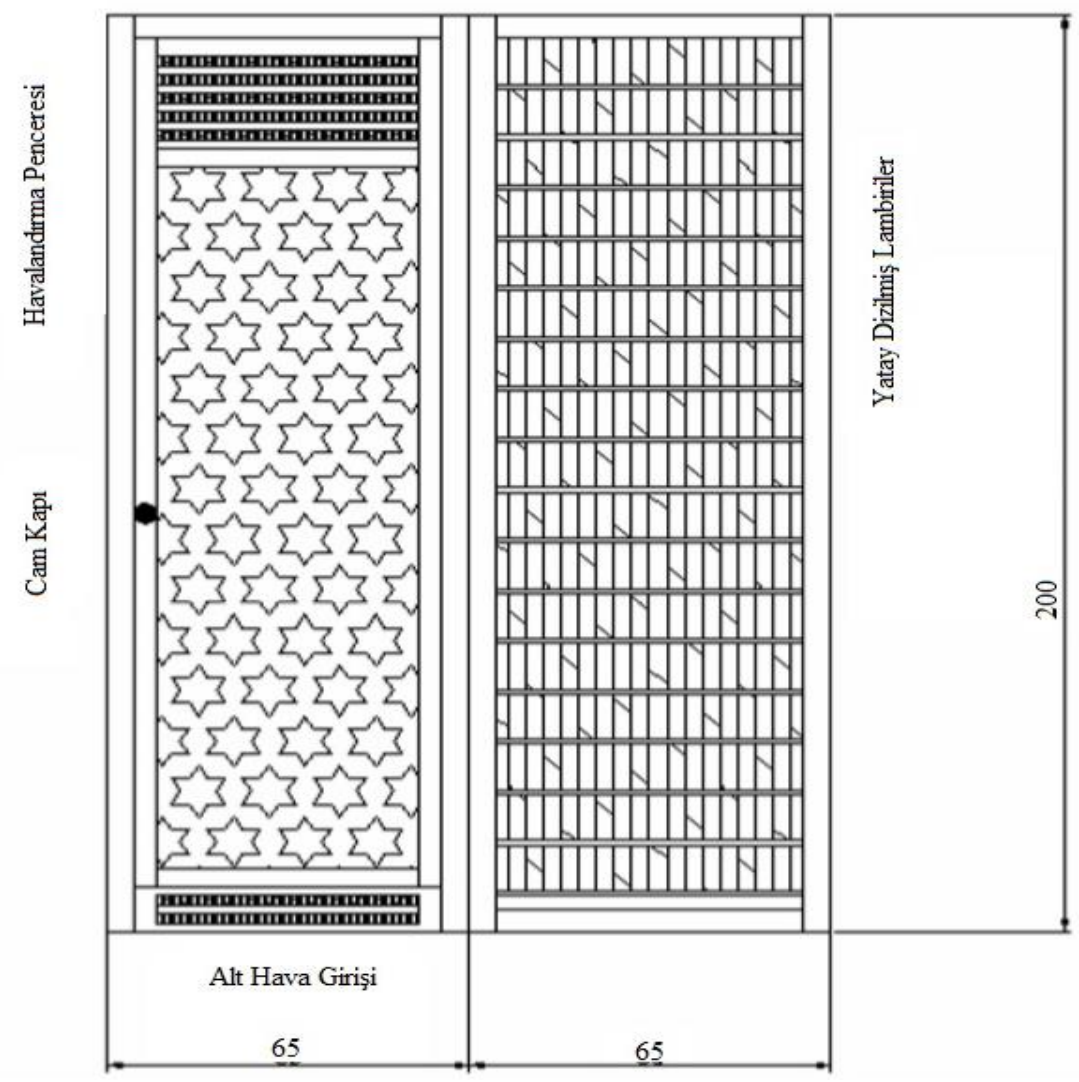

Şekil 4.Sauna kapısı ve havalandırma sistemi (cm) 
Demonte olarak tasarlanan sauna, fabrikadan veya marketten taşıma kolaylığı içerisinde kutulu olarak alınmalıdır. Taşıma kolaylığı ve paketin boyutunun küçüklüğü ile bir alternatif teşkil etmektedir. Bunun içinde sauna kiti oluşturulurken ambalajlamaya yönelik metotlar düşünülmüştür. Üretimin son aşamasında ise $80 \times 210 \mathrm{~cm}$ 'lik karton kutu ambalajda piyasaya demonte sistemde sürülebilir.

\section{Sonuç ve Öneriler}

Saunaların ilk doğuş yeri Finlandiya'dır. Arkeoloji raporlarına göre sauna bu ülkede en azından 9000 yıldan beri mevcuttur. Finlandiya nüfusunun az olmasına rağmen sauna adedi 600.000 civarındadır. İstatistik raporlarına göre her Finli yılda 61 defa sauna banyosu yapmaktadır. İhtiyarlık yaşlarında dahi Finli saunadan vazgeçmemektedir.

Son 20 yıl içinde sauna, dünyanın çeşitli ülkelerinde süratle yayılmış, hatta 30 yıl öncesine kadar sauna ismi bilinmeyen yerlere kadar girmiştir. Saunanın bütün ülkelerde süratle yayılması ve bu ülkelerde tutulmasının belli başlı sebebi bilimin son 30 y1lı içinde saunanın cildi esaslı bir şekilde temizlemekten başka, diğer hiçbir süratle mümkün olmayacak şekilde hastalıkların önüne geçmek ve bunları tedavi etmek amacını tutuğunu tespit etmiş olmasıdır. Ancak saunanın süratle ve esaslı bir şekilde yayılmasının tek sebebi, bilimin başarılı olduğu bu teşhisten ibaret olmayıp, bunun diğer bir önemli sebebi de bir defe sauna banyosu yapmış olan kimsenin, kendi vücudunda saunanın olumlu ve faydalı etkisini bizzat hissetmiş olması ve bu şekilde insanların arasında yayılmış bulunmasıdır. $\mathrm{Bu}$ sebeple bugün, dünyada aşağı yukarı hiçbir ülke yoktur ki orada sauna mevcut olmasının ve gittikçe artan bir alaka ve memnuniyetle karşılaşmasın.

Sauna yapımında dikkat edilmesi gerekli en önemli hususlardan birisi ağaç malzeme seçimidir. Sauna yapımında tercih edilen sedir ve kızılçam türü ağaçlarının ülkemizde yetişmesi de bizim için bir avantaj sayılmaktadır. Sedir ve kızılçam türü ağaçlar, yapılan araştırmalar sonucunda sauna içerisinde olumlu etkiler göstermektedirler. Ayrıca bu tür ağaçlarının imalat sırasındaki işleme kolaylığı da tercih edilme sebebidir.

Ülkemizde gerçek anlamda sauna yapan firma sayıs1 15 kadardır. Bunun sebebi üretici firmaların, birbiri ile bilgi alışverişinde bulunmamasından kaynaklanmaktadır. Diğer kuruluşların sauna yapımında, bu bilgilerden yoksun üretim yapmaları, teknolojik kurallara uyulmadığı için sauna, sauna özelliklerinde çıkarak sıcak oda halini almaktadır. Bu durum kullanıcılar üzerinde sauna hakkında yanlış bilgi edinmeye ve yanlış kullanıma yol açmaktadır.

Sauna yapımında ülkemizde firmaların atağa geçmesi gerekmektedir. Ayrıca ülkemizde sauna konusunda seminerler ve bilgilendirme toplantıları düzenlenmeli, halkımıza saunanın faydaları anlatılmalıdır. Ülkemizin ekonomik durumu da göz önüne alındığında, fiyatı uygun ve kullanışlı alternatif sauna modellerinin geliştirilmesi öncelikli araştırma konuları arasında yer almalıdır.

\section{Kaynaklar}

Bozkurt, Y., 1971. Önemli Bazı Ağaç Türleri Odunlarının Tanımı Teknolojik Özellikleri ve Kuruluş Yerleri, İstanbul Üniversitesi Orman Fakültesi Yayınları, 177, 1-50.

Çetinbank, M., ve Aksoy, A., 1987. Sauna üretimi maliyet analizi. Doktora Tezi, Hacettepe Üniversitesi Fen Bilimleri Enstitüsü, Ankara, 123s.

Glaus, Otto., 1975. "Planen Und Bauen Moderner Heilbader," Printed in Germany.

Kale, B., 2006. Saunalar ve Yapım Teknikleri. Yüksek Lisans Tezi, Dumlupınar Üniversitesi Fen Bilimleri Enstitüsü, Kütahya, 190s.

Neufert, E., 1983. Yap1 Tasarımı Temel Bilgileri: Tasarımcilar, Yap1 Sahipleri, Öğretenler ve Öğrenciler 
İçin El Kitabı, (çev: Abdullah Erkan ve Ayşe Önem Karadayılar), Güven Yayinc1lik, ISBN 3-528-18651-8, İstanbul, 534s

Türk Standartları Enstitüsü, 1992. Yayın No:Ts 1064/Kasım 1992.
URL-1, www.finnsauna.com.tr 10 Haziran 2006.

URL-2, www.sankurt.com. 10 Haziran 2006.

URL-3， www.ayhavuz.com. 10 Haziran 2006. 